\title{
O CONCEITO DE ELETRONEGATIVIDADE NA EDUCAÇÃO BÁSICA E NO ENSINO SUPERIOR
}

\author{
Camila Maria Andrade dos Santos, Ricardo Alexandre Galdino da Silva e Edson José Wartha* \\ Departamento de Química, Universidade Federal de Sergipe, Campus Prof. Alberto Carvalho, 49500-000 Itabaiana - SE, Brasil
}

Recebido em 22/3/11; aceito em 30/6/11; publicado na web em 8/8/11

\begin{abstract}
THE ELECTRONEGATIVITY CONCEPT IN THE SECONDARY EDUCATION AND IN THE UNIVERSITY EDUCATION. The goal of this study was to examine the means used by textbook authors to introduce, define, and explain the electronegativity concept in high school and introductory college chemistry textbooks. Results obtained showed that most textbooks lacked history precedence and did not deal with the conceptual understanding and manifesting a strong standardization of characteristics that, from our point of view, do not favor the teaching-learning of the electronegativity concept.
\end{abstract}

Keywords: electronegativity; historical approach; textbooks.

\section{INTRODUÇÃO}

O saber escolar nas disciplinas científicas se constitui a partir da relação com diferentes saberes sociais como, por exemplo, os saberes do cotidiano, saberes do senso comum e os saberes científicos. ${ }^{1} \mathrm{O}$ reconhecimento da importância de ensinar o conhecimento científico não significa apresentá-lo da mesma maneira como os cientistas apresentam em seus congressos. A escola, professores e autores de materiais didáticos podem e realizam aproximações do conhecimento científico que os cientistas reconhecem como válido, para que o saber científico possa se constituir em saber escolar. ${ }^{2}$

Esse processo de aproximação dos saberes científicos em saberes escolares, também conhecido como transposição didática, didatização ou recontextualização existe devido ao fato de que o funcionamento do saber escolar é diferente do funcionamento do saber científico, ou seja, existe um processo de transformação do objeto do saber em objeto de ensino. Tais processos de transformação dos saberes científicos em saberes escolares se manifestam de maneira mais explícita nos livros didáticos, uma vez que nestes manuais se encontram os conhecimentos a serem ensinados. Negar ou ignorar a transposição didática nos livros é conceber que o conhecimento ali presente é uma reprodução fiel de todos os conhecimentos desenvolvidos pela ciência, o que não é uma verdade. ${ }^{3}$

O conceito de eletronegatividade foi introduzido por J. J. Berzelius, em 1811, que o definiu como sendo a capacidade que um átomo tem de atrair para si os elétrons. Linus Pauling aprofundou os estudos de Berzelius e, em 1931, propôs a primeira escala de eletronegatividade. Pauling procurou determinar diferenças entre as energias de ligações homonucleares e ligações heteronucleares (entre átomos diferentes) assumindo que se duas moléculas diatômicas homonucleares interagem para formar moléculas diatômicas heretonucleares, a energia de ligação nesta última deveria ser uma média de duas energias de ligações homonucleares na molécula original (Postulado da adição de ligações covalentes normais).

$$
\mathrm{D}(\mathrm{A}-\mathrm{B})=1 / 2[\mathrm{D}(\mathrm{A}-\mathrm{A})+\mathrm{D}(\mathrm{B}-\mathrm{B})]
$$

$\mathrm{D}(\mathrm{A}-\mathrm{A})=$ energia de ligação na espécie homonuclear $(\mathrm{A}-\mathrm{A})$;
$\mathrm{D}(\mathrm{B}-\mathrm{B})]=$ energia de ligação na espécie homonuclear (B-B); D(A-B) = energia de ligação na espécie (A-B).

Pauling esperava que, se uma ligação covalente normal A-B fosse semelhante em caráter com as ligações A-A e B-B, o valor da energia de ligação da molécula A-B seria intermediário entre os valores de energia de ligação das moléculas A-A e B-B. Entretanto, observou-se que a energia de ligação heteronuclear real era maior que a média esperada (Equação 2) e, que esta aumentava conforme os átomos se tornavam diferentes em relação a uma propriedade, que os químicos chamaram de eletronegatividade. Tal propriedade foi definida como o poder de um átomo, em uma molécula, de atrair elétrons para si mesmo. ${ }^{4}$

$$
\mathrm{D}(\mathrm{A}-\mathrm{B})=1 / 2[\mathrm{D}(\mathrm{A}-\mathrm{A})+\mathrm{D}(\mathrm{B}-\mathrm{B})]+\Delta
$$

$\Delta=$ diferença entre a energia de ligação real e a média aritmética entre as energias de ligação A-A e B-B.

Pauling definiu esta diferença como:

$$
\Delta=\mathrm{D}(\mathrm{A}-\mathrm{B})-1 / 2[\mathrm{D}(\mathrm{A}-\mathrm{A})+\mathrm{D}(\mathrm{B}-\mathrm{B})]
$$

Assumindo que, caso o postulado da adição seja verdadeiro, a diferença entre a energia de ligação real seria sempre maior ou igual à média aritmética entre as energias das ligações A-A e B-B. E assim a diferença $(\Delta)$ nunca seria negativa.

O postulado da adição foi válido para um grande número de ligações simples e os valores de $\Delta$ puderam ser usados para elaborar uma escala de eletronegatividade dos elementos. Entretanto, em alguns casos, alguns resultados mostraram que o postulado da adição das energias de ligações covalentes normais não era válido para hidretos de metais alcalinos, pois os valores de $\Delta$ encontrados eram negativos, fato que contradizia a consideração de que os valores de $\Delta$ seriam sempre positivos. Nesse caso, houve a necessidade da substituição do postulado da adição por um postulado similar que envolvesse a média geométrica das energias de ligações D(A-A) e D(B-B) (Postulado da média geométrica). Nesse novo postulado, a energia de uma ligação covalente normal entre átomos A e B seria igual a $[\mathrm{D}(\mathrm{A}-\mathrm{A}) \cdot \mathrm{D}(\mathrm{B}-\mathrm{B})]^{1 / 2}$ e, como consequência, a quantidade $\Delta$ ' foi definida como:

$$
\Delta^{\prime}=\mathrm{D}(\mathrm{A}-\mathrm{B})-[\mathrm{D}(\mathrm{A}-\mathrm{A}) \cdot \mathrm{D}(\mathrm{B}-\mathrm{B})]^{1 / 2}
$$


$\Delta^{\prime}=$ diferença entre a energia de ligação real e a média geométrica entre as energias de ligação A-A e B-B.

A partir dos valores de $\Delta$ e $\Delta^{\prime}$ atribuídos para as energias de ligações de moléculas simples, foi possível formular uma escala de eletronegatividade dos elementos. Pauling calculou os valores de $\Delta^{\prime}$ para ligações entre átomos de não metais e percebeu que os valores obtidos não satisfaziam uma relação linear. Assim, eles não poderiam ser representados como diferenças de termos característicos de dois átomos em uma ligação. Entretanto, a raiz quadrada dos valores de $\Delta^{\prime}$ satisfazia aproximadamente uma relação deste tipo. Desse modo, as diferenças de eletronegatividade foram obtidas a partir das relações abaixo, considerando os valores 23 (Equação 5) e 30 (Equação 6) como fatores de correção com unidades de energia, o que torna a diferença de eletronegatividade uma grandeza adimensional. ${ }^{4}$

$\left(\chi_{\mathrm{A}} \chi_{\mathrm{B}}\right)=\Delta=(23)^{-1 / 2}\{\mathrm{D}(\mathrm{A}-\mathrm{B})-1 / 2[\mathrm{D}(\mathrm{A}-\mathrm{A})+\mathrm{D}(\mathrm{B}-\mathrm{B})]\}^{1 / 2}$

ou

$\left(\chi_{\mathrm{A}-} \chi_{\mathrm{B}}\right)=\Delta^{\prime}=(30)^{-1 / 2}\left\{\mathrm{D}(\mathrm{A}-\mathrm{B})-[\mathrm{D}(\mathrm{A}-\mathrm{A}) \cdot \mathrm{D}(\mathrm{B}-\mathrm{B})]^{1 / 2}\right\}^{1 / 2}$

$\chi_{\mathrm{A}}=$ eletronegatividade do átomo $\mathrm{A} ; \chi_{\mathrm{B}}=$ eletronegatividade do átomo B.

Como consequência, apenas diferenças de eletronegatividade foram definidas e, portanto, no processo de construção de uma escala foi necessário escolher um ponto de referência arbitrário. Como o hidrogênio forma ligações covalentes com uma grande variedade de elementos, acabou sendo escolhido como referência com uma eletronegatividade fixada em 2,1. Os valores de eletronegatividade dos demais elementos foram obtidos a partir da comparação com a eletronegatividade do hidrogênio. Após o trabalho de Pauling, diversos estudos sobre eletronegatividade foram realizados e outras escalas de eletronegatividade foram propostas, com base em diferentes parâmetros atômicos e propriedades físicas. Entre essas escalas, encontram-se as escalas de Mülliken (1934), de Allred-Rochow (1958) e de Sanderson (1951).

Em 1934, Mülliken propôs uma escala de eletronegatividade absoluta, na qual sugeria que esta deveria ser a média aritmética da energia necessária para remover um elétron de um átomo na fase gasosa (energia de ionização) e da energia liberada quando um elétron é adicionado a um átomo em fase gasosa (afinidade eletrônica). Mülliken sugeriu que esses valores deveriam corresponder a um estado de valência apropriado, ou seja, a eletronegatividade dependeria do estado de oxidação do elemento. ${ }^{5}$

Allred e Rochow, em 1958, consideraram que a eletronegatividade deveria estar relacionada com a força eletrostática experimentada por um elétron na camada de valência do átomo causada por sua carga nuclear efetiva. ${ }^{6}$ Consideravam a eletronegatividade uma medida da efetividade das cargas nucleares sobre os orbitais vazios mais externos e que, portanto, deveria existir uma relação íntima entre estrutura atômica e esta propriedade. Dessa forma, esta propriedade não pode ser interpretada apenas como um número, mas também, como uma consequência da estrutura atômica. Fato que se torna mais nítido quando o efeito de blindagem da carga nuclear de um átomo é analisado e percebem-se que os elétrons mais externos não são tão efetivos quanto os mais internos, permitindo assim que a carga nuclear efetiva interfira no número de elétrons de valência de um dado átomo. ${ }^{6}$

Sanderson, em 1951, notou a relação entre eletronegatividade e tamanho atômico. Considerou eletronegatividade como uma função da densidade relativa das nuvens eletrônicas ao redor do núcleo atômico. Reconheceu que a tendência natural de alguns átomos com alta eletrogenatividade é adquirir cargas parciais negativas causando expansão da eletrosfera para uma condição menos compactada (menor densidade eletrônica). O resultado natural da perda parcial de elétrons de um átomo de baixa eletronegatividade é a contração da eletrosfera para uma condição mais compactada (maior densidade eletrônica). ${ }^{7}$

Pearson, em 1990, sugeriu que escalas diferentes de eletronegatividade têm aplicações distintas e que cada uma delas está correta, dentro de sua própria área de aplicação. ${ }^{8}$ Uma escala de eletronegatividade deve refletir adequadamente a particularidade dos elementos e explicar satisfatoriamente várias propriedades físicas e químicas dos compostos. A escala mais extensamente utilizada é a de Pauling, pois esta tem sido efetivamente usada para predizer a polaridade de uma ligação, a solubilidade e o ponto de fusão de compostos. A confiabilidade das demais escalas é geralmente verificada através da comparação com a escala original. Desta forma, ao trabalhar com eletronegatividades atômicas, recomendam-se os valores propostos por Pauling e revisados por Allred e Rochov. ${ }^{9}$

Analisando os períodos da Tabela Periódica dos Elementos Químicos, observa-se que, da esquerda para a direita, acontece um aumento na carga nuclear efetiva, devido a novos elétrons que são adicionados em uma mesma camada eletrônica. Devido ao emparelhamento dos elétrons, a blindagem da carga nuclear sobre um elétron pelos demais não é muito eficiente e, portanto, a carga nuclear efetiva cresce. Nesse caso, a carga nuclear efetiva atrai o elétron para o núcleo, tornando o átomo mais compactado, ou seja, o aumento da carga resulta em uma contração obrigatória da nuvem eletrônica, provocando uma diminuição do raio atômico.

$\mathrm{O}$ efeito mais intenso da carga nuclear efetiva sobre um raio menor resulta em um contínuo aumento da densidade eletrônica média e, consequentemente, um aumento da eletronegatividade, conforme proposto por Sanderson, em 1951. ${ }^{7}$ Ao longo do grupo, a carga nuclear efetiva cai devido ao aumento do número quântico principal, ou seja, ela decresce porque novas camadas eletrônicas são ocupadas. Tal ocupação provoca a expansão da nuvem eletrônica, levando ao aumento do raio atômico e à diminuição da densidade eletrônica média, o que não significa necessariamente uma diminuição da eletronegatividade. Fenômeno que se torna mais visível quando são analisados os valores recomendados de eletronegatividades. ${ }^{9}$

É possível notar, ao longo do grupo, que apesar dos átomos possuírem valores decrescentes de densidade eletrônica, alguns deles apresentam a mesma eletronegatividade como, por exemplo, $\mathrm{Ke} \mathrm{Rb}$; Tc e Re; Ru e Os. Assim, a antiga suposição de que a eletronegatividade decresce com o aumento do número atômico ao longo do grupo não é realmente verdade e não deve ser esperada. Pode-se apenas dizer que existe uma tendência de isto ocorrer. ${ }^{10}$

Quanto mais eletronegativo for um elemento maior será a atração entre núcleo e seus elétrons, como proposto por Allred e Rochow, em 1958. Deste modo, será preciso fornecer uma grande quantidade de energia para que ele perca um elétron. Assim, quanto maior for sua eletronegatividade, maior será a energia necessária para remover um elétron, ou seja, maior a energia de ionização. Portanto, a tendência dele não será perder, mas sim ganhar cargas negativas, pois o mesmo possui grande afinidade por elétrons. Uma alta afinidade eletrônica significa que uma grande quantidade de energia é liberada quando um elétron é adicionado a um átomo em fase gasosa. Então, quanto mais eletronegativo for um átomo, mais facilmente ele acomodará elétrons em sua camada externa, isto é, maior será sua afinidade eletrônica. ${ }^{10}$

Em outras palavras, elementos que possuem altos valores de energia de ionização e afinidade eletrônica perdem elétrons com dificuldade e tendem a ganhá-los, logo, são classificados como muito eletronegativos. Reciprocamente, se a energia de ionização e a afinidade eletrônica são baixas muito pouca energia é necessária para que o elemento ceda elétrons, então ele tende a doá-los, assim sua eletronegatividade é baixa, conforme Mülliken afirmou em $1934 .^{5}$ 


\section{A RELAÇÃO ENTRE O PROCESSO DE ENSINO DE QUÍMICA E OS LIVROS DIDÁTICOS}

No Brasil, a história do Ensino de Ciências, em particular o Ensino de Química, tem revelado um quadro repleto de improvisações, no qual o docente, em decorrência de uma formação inadequada, utiliza o livro didático como alicerce de suas aulas. ${ }^{11,12}$ Sendo um dos recursos mais utilizados no processo de ensino e aprendizagem, acabam por exercer forte influência no planejamento e execução do trabalho do professor em sala de aula, determinando a ordem dos conteúdos e, até mesmo, a abordagem metodológica. Diferentes trabalhos revelam certa correlação entre a má qualidade de ensino e a má qualidade da literatura didática. Apesar da grande variedade de títulos disponíveis ainda há muitas semelhanças entre as informações, os exemplos, os exercícios e atividades propostas contidas nesses compêndios. ${ }^{12}$

Há relatos na literatura de que em aulas de Química, geralmente, são trabalhados conceitos distintos que nem sempre são objetos de uma análise adequada. Conceitos que são, na maioria das vezes, abordados como meras definições capazes apenas de instrumentalizar os estudantes na resolução de exercícios esquemáticos. Nesse processo, o conceito científico é frequentemente retirado de seu contexto original e transposto para o contexto escolar de maneira empobrecida e/ou equivocada. Por outro lado, conceitos que se interrelacionam são trabalhados de modo desconexo, como se não houvesse relação alguma entre eles. ${ }^{13}$

Pesquisas realizadas a partir de análise de livros didáticos de Química do Ensino Médio revelam que o conceito de eletronegatividade geralmente é definido como: "capacidade que os átomos de determinado elemento possuem para atrair elétrons" ou "força de atração exercida sobre os elétrons de uma ligação". Nesse caso, também foi observado que o conceito de eletronegatividade é apresentado fora de sua historicidade e que, algumas vezes, é confundido com afinidade eletrônica e no que se refere às aplicações, era usado apenas para definir a polaridade das ligações covalentes. ${ }^{14}$

Sendo o livro didático um recurso bastante utilizado como mediador no processo de ensino-aprendizagem e considerando-se a relevância do conceito de eletronegatividade na compreensão de assuntos importantes no âmbito da Química, pretende-se neste trabalho resgatar o conceito de eletronegatividade em seu contexto original e, ao mesmo tempo, realizar uma análise do processo de inserção histórica deste conceito nos livros didáticos de Química no Ensino Médio e Superior, procurando identificar aproximações e distanciamento em relação ao conhecimento de referência.

\section{O CONCEITO DE ELETRONEGATIVIDADE EM LIVROS DIDÁTICOS DE QUÍMICA}

Para avaliar a abordagem do conceito de eletronegatividade no Ensino de Química foram analisados livros didáticos do Ensino Médio e Superior. Ao todo fizeram parte da análise 6 livros didáticos do Ensino Médio e 7 do Ensino Superior, sendo 5 de Química Geral e 2 de Química Inorgânica.

O critério de seleção dos livros didáticos para o Ensino Médio era que fossem utilizados como livros-texto nas escolas públicas e particulares do Estado de Sergipe. Optamos por avaliar 3 livros de Química do Ensino Médio aprovados pelo PNLEM-2008 e porque foram selecionados em maior quantidade pelos professores da rede pública do Estado de Sergipe e 3 livros que foram reprovados pelo PNLEM-2008, mas que, por mais de uma década, foram os livros mais adotados nas escolas públicas e particulares do Estado de Sergipe. Para os livros didáticos no Ensino Superior, o critério norteador foi o fato deles constarem como bibliografia básica nos programas das disciplinas de Química Geral e Química Inorgânica no curso de
Licenciatura em Química de uma universidade pública do Estado de Sergipe.

A escolha por avaliar livros didáticos tanto de Ensino Médio como do Ensino Superior se deve ao fato de que os livros didáticos de Ensino Médio, geralmente utilizam, como referências, os livros didáticos do Ensino Superior. A análise tanto de livros didáticos do Ensino Médio como do Ensino Superior permite que se identifiquem aproximações e distanciamentos em relação ao conceito de eletronegatividade e de como ocorre a transformação do saber científico em saber escolar, considerando que no nível superior há uma maior aproximação em relação ao conhecimento de referência e que há um afastamento maior no nível médio. Todos os livros didáticos do Ensino Superior objeto deste estudo são usados como referência de pelo menos um livro didático de Ensino Médio. Foram analisados livros de Química Geral e de Química Inorgânica, pois nestes livros o conceito de eletronegatividade tem papel destacado no capítulo que trata das ligações químicas.

Este trabalho foi desenvolvido através da análise de conteúdo, semelhante àquela adotada por $\mathrm{Niaz}^{15}$ na análise de livros didáticos de Química na Venezuela. Propusemos a realização de uma análise que permitisse verificar como o conteúdo relacionado ao conceito de eletronegatividade vem sendo abordado nos livros didáticos, tomando como base a construção histórica acerca do conceito eletronegatividade. Foram propostos critérios que pudessem revelar como o conceito de eletronegatividade é tratado nos livros didáticos. A definição desses critérios pretendeu identificar o modo de apresentação de conteúdos fundamentais e aspectos conceituais contidos nos livros didáticos relacionados ao tema histórico investigado. A definição destes critérios levou em conta os seguintes aspectos: a abordagem conceitual do termo eletronegatividade; a contextualização do tema e, a relação com aspectos históricos.

Os livros didáticos analisados estão indicados na Tabela 1, LDM (Livros Didáticos do Ensino Médio), e LDS (Livros Didáticos do Ensino Superior).

\section{Livros didáticos de Química no Ensino Médio e o conceito de eletronegatividade}

Através da análise dos livros didáticos de Química do Ensino Médio foi possível identificar que estes trazem pouca informação sobre o termo eletronegatividade. Geralmente o conceito é apresentado a partir de uma abordagem tradicional, em que é mostrada apenas sua definição seguida de um esquema de setas que mostra a variação da eletronegatividade dentro da Tabela Periódica. Como informação histórica, a maioria dos livros cita apenas que o termo eletronegatividade foi originalmente proposto por Linus Pauling, não associando a definição mostrada ao referido autor. Entretanto, como este é o único propositor citado, subentende-se que a definição apresentada seja a dele.

Nos textos analisados, foram encontradas as seguintes definições para o conceito de eletronegatividade: (1) "Capacidade que um átomo tem de atrair para si o par eletrônico de uma ligação covalente", essa definição foi encontrada de forma semelhante nos livros LDM1, LDM2 e LDM3; (2) "Tendência que o átomo de determinado elemento apresenta para atrair elétrons quando se encontra ligado a outro átomo", em LDM4; (3) "Tendência que um átomo possui de atrair elétrons para perto de si quando se encontra ligado a outro elemento químico diferente, numa substância composta", em LDM5 e (4) "Força exercida sobre os elétrons de uma ligação", em LDM6.

Ao compararmos tais definições com a definição original de Linus Pauling: "the power of an atom in a molecule to attract electrons to itself". ${ }^{1}$ Atentando-se apenas para esta definição, através de uma ótica descontextualizada, seria possível considerar coerentes as colocações 
Tabela 1. Relação dos livros didáticos de Química usados na análise

\begin{tabular}{ll}
\hline Códigos & Livros didáticos de Química \\
\hline LDM1* $^{*}$ & $\begin{array}{l}\text { Feltre, R.; Química geral, 6a ed., São Paulo: Editora Moderna, } \\
\text { 2004. }\end{array}$ \\
LDM2 & $\begin{array}{l}\text { Lembo, A.; Química: Realidade e Contexto, vol. 1, São Paulo: } \\
\text { Editora Ática, 2000. }\end{array}$ \\
LDM3* & $\begin{array}{l}\text { Santos, W. L. P. et al.; Química \& Sociedade, São Paulo: Editora } \\
\text { Nova Geração, 2005. }\end{array}$ \\
LDM4* & $\begin{array}{l}\text { Peruzo, F. M.; Canto, E. L.; Química na abordagem do cotidiano, } \\
\text { 3a ed., São Paulo: Editora Moderna, vol. 1, 2003. }\end{array}$
\end{tabular}
$3^{a}$ ed., São Paulo: Editora Moderna, vol. 1, 2003.

LDM5 Fonseca, M. R. M.; Interatividade química: cidadania, participação e transformação, São Paulo: FTD, 2003.

LDM6 Usberco, J.; Química I: Química Geral, 9a ed., São Paulo: Editora Saraiva, vol. 1, 2002.

LDS1 Mahan, B. H.; Myers, R. J.; Química: Um Curso Universitário, Trad. Henrique E. Toma et al.; 2a ed., São Paulo: Edgard Blücher, 1993.

LDS2 Atkins, P.; Jones, L.; Princípios de química: questionando a vida moderna e o meio ambiente, Trad. Ricardo Bicca de Alencastro; $3^{\text {a }}$ ed. Porto Alegre: Bookman, 2006.

LDS3 Russel, J. B.; Química Geral, Trad. Márcia Guekezian et al.; $2^{a}$ ed., vol. 1, São Paulo: Makron Books, 1994.

LDS4 Brown, T. L.; Lemay, H. E.; Bursten, B. E.; Química: a ciência central, Trad. Robson Matos; 9ª ed., São Paulo: Pearson, 2007.

LDS5 Kotz, J. C.; Treichel, P. M. Jr.; Química Geral e Reações Químicas, Trad. José Alberto Bonaparte e Oswaldo Barcia; São Paulo: Thomson, vol. 1, 2005.

LDS6 Lee, J. D.; Química inorgânica não tão concisa, Trad. Henrique E. Toma et al.; $5^{\text {a }}$ ed., São Paulo: Edgard Blücher, 2000.

LDS7 Shriver, D. F.; Atkins, P.; Química Inorgânica, Trad. Maria Aparecida Gomes; 4ª ed., Porto Alegre: Bookman, 2008.

* Livros didáticos de Química aprovados no PNLEM-2008.

(1) (2) e (3) encontradas em vários livros didáticos. Entretanto, ao se observar o contexto no qual se deu o surgimento deste conceito (a partir de valores de energia de ligação de moléculas simples), tornase claro que só faz sentido falar em eletronegatividade quando um átomo está ligado a outro átomo de um elemento químico diferente. Desta forma, fundamentando-se no trabalho de Pauling, a maneira mais coerente dos livros didáticos apresentarem eletronegatividade seria de modo semelhante ao mostrado em LDM5.

Em LDM6 foi encontrada após definição mostrada em (4) que "existem algumas escalas que relacionam a eletronegatividade dos elementos, sendo que a escala de Pauling é a mais utilizada. Os valores fornecidos por Pauling foram provenientes de uma relação entre a energia de ionização e a afinidade dos elementos". Na primeira frase da citação acima, pode-se observar que é mencionada a existência de algumas escalas de eletronegatividade, porém o único propositor citado é Linus Pauling, o que conduz à ideia de que a definição apresentada em (4) seria deste. Se esse for o caso, esta colocação encontra-se equivocada, pois ao mostrar o conceito de eletronegatividade desta forma, o leitor é induzido a pensar que eletronegatividade possui unidade de força (Newton). Porém, ao se explorar o contexto de produção e de construção do conceito proposto por Linus Pauling fica claro que esta propriedade não possui unidade.

Analisando a segunda frase da citação acima, observa-se que o autor comete o equívoco de dizer que a escala elaborada por Linus Pauling foi proveniente de uma relação entre a energia de ionização e a afinidade dos elementos (afinidade eletrônica dos elementos). Entretanto, como já mencionado anteriormente, os valores obtidos por
Linus Pauling foram provenientes das energias de ligações e não de uma relação entre energia de ionização e afinidade eletrônica. A escala construída a partir destes parâmetros foi elaborada por Mülliken.

Também foi possível constatar que, na maioria dos livros analisados para o Ensino Médio, a eletronegatividade não é mostrada como uma grandeza relativa e que, além disso, os textos não procuram explicar as relações entre eletronegatividade e outras propriedades periódicas. A única relação encontrada, em apenas dois livros (LDM1 e LDM5) foi de que a eletronegatividade geralmente aumenta com a diminuição do raio atômico, porém, não mostram a explicação do motivo pelo qual ocorre tal variação. Em todos os livros analisados, independentemente de terem sido aprovados ou reprovados no PNLEM de 2008, continua-se a utilizar somente a definição de eletronegatividade de Linus Pauling, independentemente de terem sido inúmeros os estudos inerentes a este conceito. É pouco frequente encontrar em um livro didático outra definição de eletronegatividade que não a de Pauling.

Ainda foi possível observar que, em geral, os livros didáticos têm utilizado um esquema de setas (Figura 1) na tentativa de facilitar a visualização da variação da eletronegatividade na Tabela Periódica. Contudo, deve-se tomar cuidado ao trabalhar com este esquema, pois ele pode ser equivocadamente compreendido como uma "regra" a ser seguida, a qual indica que a eletronegatividade aumenta da esquerda para direita ao longo do período e diminui descendo o grupo da Tabela Periódica, levando os casos que não seguem esta "regra" a serem interpretados como exceções.

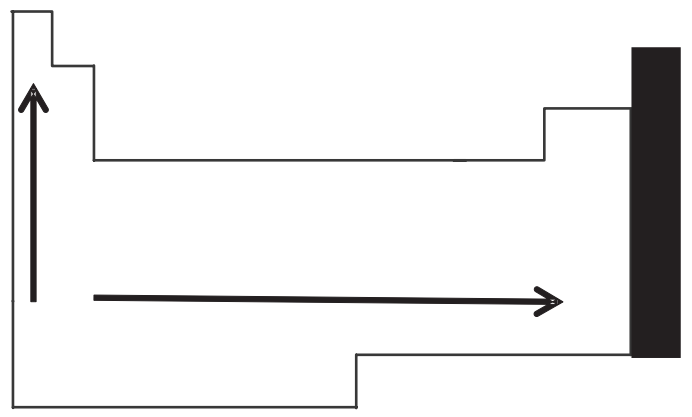

Figura 1. Esquema de setas mostrando a variação da eletronegatividade dentro da tabela periódica

O esquema de setas, da maneira como vem sendo empregado, não tem contribuído para estimular o raciocínio dos alunos. Acredita-se que ele pode servir como ferramenta no auxílio da aprendizagem dos alunos, desde que seja apresentado em um último momento, como uma maneira de resumir as tendências identificadas. De tal forma que fique claro que não se trata de uma regra a ser seguida, mas sim, de uma representação geral de uma tendência existente.

Nesta Figura, os elementos da coluna em preto são os gases nobres, que neste caso estão em destaque por serem considerados inertes. Como já existem relatos de compostos formados por gases nobres, tal qual o xenônio ( $\mathrm{XeF}_{6}, \mathrm{XeF}_{2}$, entre outros), isso parece sugerir que desconsiderar todos os elementos da coluna dos gases nobres, como atualmente é feito, também pode ser um equívoco.

\section{Livros didáticos de Química no Ensino Superior e o conceito de eletronegatividade}

Na análise dos livros didáticos de Química utilizados no Ensino Superior verificamos que os livros de Química Geral deixam claro que o conceito de eletronegatividade é um parâmetro que só se aplica a átomos em moléculas. Porém, na maior parte destes materiais não é mencionado que eletronegatividade surge apenas quando átomos 
de elementos químicos diferentes estão unidos por uma ligação. No que se refere às informações históricas, apenas 3 livros citam que a primeira escala de eletronegatividade foi proposta por Linus Pauling e que diferentes escalas de eletronegatividade têm sido propostas com base em parâmetros experimentais distintos. Entretanto, somente 2 destes livros (LDS1 e LDS2) apresentam a elaboração da escala original, mostrando que se trata de uma escala relativa. Além do que estes mesmos materiais didáticos foram os únicos a citar Mülliken como outro pesquisador que também estudou esta propriedade.

No que diz respeito às ligações com outras propriedades, a eletronegatividade tem sido relacionada com: raio atômico (LDS1 e LDS3), carga nuclear efetiva (LDS3), energia de ionização e a afinidade eletrônica (LDS2). Os demais livros apresentam definições muito semelhantes aos livros didáticos de Ensino Médio (LDS4 e LDS5), ou seja, utilizam somente a definição de eletronegatividade de Linus Pauling, independentemente dos outros estudos sobre eletronegatividade. Além dessa visão limitada, é possível verificar que existe uma defasagem entre o nível em que é abordado o conceito de eletronegatividade e o nível em que seria desejável e, até mais vantajosa, a sua inserção no ensino de Química, podendo ser abordado de modo mais abrangente e, posteriormente, ser melhor usado na explicação dos vários tipos de ligações químicas.

No primeiro caso, os autores Mahan e Myers (LDS1) informam apenas que átomos menores são mais eletronegativos do que átomos maiores. No segundo, o autor Russel (LDS3) menciona apenas que a eletronegatividade tende a crescer da esquerda para a direita através de um período da Tabela Periódica, devido ao aumento da carga nuclear efetiva e que, descendo um grupo da Tabela Periódica, a eletronegatividade diminui na medida em que a camada de valência se torna mais afastada do núcleo, ou seja, aumenta conforme o raio dos átomos se torna maior. Já no terceiro, os autores Atkins e Jones (LDS2) relacionam a variação da eletronegatividade com o aumento ou diminuição das cargas parciais. Quando se têm pequenas diferenças de eletronegatividade, as cargas parciais são muito pequenas e, quando se aumenta a diferença de eletronegatividade, também aumentam as cargas parciais. Nessa abordagem, estes autores demonstram a partir das ideias de Robert Mülliken, que a eletronegatividade é a média entre a energia de ionização e a afinidade eletrônica do elemento.

A partir da análise dos livros de Química Inorgânica (LDS6 e LDS7), observou-se que a eletronegatividade é apresentada como uma propriedade aplicada somente a átomos em moléculas. Foi possível identificar, por meio da observação dos dados históricos fornecidos ao longo dos textos, que esses materiais mostram, embora não de forma explícita, que eletronegatividade surge apenas quando átomos diferentes estão ligados. Identificamos que esses livros didáticos apresentam uma abordagem histórica um pouco mais detalhada para o conceito de eletronegatividade. Além de mostrarem como foi construída a escala de Linus Pauling apresentam também aspectos históricos das escalas de Mülliken e de Allred-Rochow.

Foi possível observar que um dos livros (LDS6) apresenta uma abordagem histórica mais detalhada da escala original, mostrando passo a passo como foram encontrados os valores fornecidos na escala de Pauling, deixando claro que em seus cálculos Pauling encontrou apenas valores das diferenças de eletronegatividade entre dois átomos e que, para obter valores individuais para cada átomo, foi necessário supor um valor de referência. Também afirma que, devido à existência de poucos valores tabelados de afinidade eletrônica, a abordagem baseada nas energias de formação é mais comum. Assim, embora o método de Mülliken apresente uma base teórica mais simples permitindo a obtenção de valores de eletronegatividade para estados de oxidação diferentes, o método de Linus Pauling é preferencialmente, o mais usado. O segundo livro de Química Inorgânica (LDS7) não faz qualquer menção a este fato. Porém, ambos os livros de Química
Inorgânica citam que átomos pequenos são mais eletronegativos, porque atraem mais fortemente os elétrons que os átomos grandes, como também que átomos pequenos com camadas eletrônicas fechadas têm maior probabilidade de atrair um elétron para si mais do que um átomo com poucos elétrons de valência. Porém, apenas um dos livros didáticos (LDS7) explica como eletronegatividade está interrelacionada com a energia de ionização e com a afinidade eletrônica.

\section{CONSIDERAÇÕES FINAIS}

A partir do estudo da construção histórica do conceito de eletronegatividade foi possível perceber que eletronegatividade é uma propriedade relativa e que só faz sentido falar nela quando átomos de elementos químicos diferentes formam uma ligação e, que eletronegatividade se refere a um átomo numa molécula. Também foi possível verificar que os valores de eletronegatividade dependem do ambiente químico no qual os átomos se encontram.

Por meio da análise dos livros didáticos do Ensino Médio, identificamos que a maioria dos LDM apresenta o conceito de eletronegatividade de maneira ahistórica e descontextualizada. Os textos, de maneira geral, não procuram explicar a relação entre eletronegatividade e outras propriedades periódicas. O conceito de eletronegatividade geralmente é apresentado de forma impositiva, sem qualquer fundamentação que induza o aluno a levantar questionamentos e desenvolva ações práticas sobre a importância e necessidade da aprendizagem deste conceito, o que, de nosso ponto de vista, faz com que o mesmo não visualize nenhuma finalidade no seu estudo, a não ser memorizá-lo para ser promovido de série. Verificamos também que os livros didáticos de Ensino Médio utilizam somente a definição de eletronegatividade de Linus Pauling, fato que foi observado tanto nos livros aprovados, bem como nos reprovados pelo PNLEM-2008.

Em relação aos livros didáticos de Química Geral, verificamos que a maioria aborda o conceito de eletronegatividade de maneira que não há um avanço em relação ao conceito abordado nos livros didáticos de Ensino Médio. Ao invés de um distanciamento, há uma grande aproximação entre os livros de Ensino Médio e de Química Geral no que se refere à eletronegatividade. Dificilmente um aluno, no estudo inicial da Química, em nível de graduação poderá tomar consciência de que o mesmo elemento pode ter cargas distintas em moléculas distintas. A posterior compreensão ou explicação por parte do professor para a razão deste fato abre as portas para um ensino em que se privilegie a compreensão dos conteúdos e não apenas sua memorização.

Dos livros analisados, apenas 2 deles trazem uma abordagem mais profunda e contextualizada do conceito de eletronegatividade. Quanto à ligação com outros conceitos, dos 5 livros didáticos analisados, apenas 3 trazem alguma relação entre eletronegatividade e alguma outra propriedade periódica. Por outro lado, nos livros didáticos de Química Inorgânica, verificamos que abordam o conceito de eletronegatividade de maneira mais coerente com o processo de construção histórica do conceito. Fato que era esperado devido à maior proximidade deste conhecimento com o conhecimento de referência. Entretanto, acredita-se que estes materiais podem realizar uma abordagem mais detalhada das relações existentes entre eletronegatividade, carga nuclear efetiva, raio atômico, energia de ionização e afinidade eletrônica.

No Ensino Superior, seria interessante uma abordagem mais detalhada dos aspectos históricos das diversas escalas de eletronegatividade construídas no desenvolvimento da ciência, desde as mais antigas como a de Mülliken (1934), até as mais recentes como a de Allen (1989). É interessante mostrar, aos estudantes de química, um panorama atual da eletronegatividade, pois existem novas propriedades, como as cargas atômicas baseadas na teoria do funcional de 
densidade, em que é possível determinar as propriedades das ligações químicas com mais eficácia.

Podemos concluir que tanto os livros de Ensino Médio quanto os de Ensino Superior manifestam uma forte padronização de características que, do nosso ponto de vista, são desfavoráveis ao processo de ensino-aprendizagem do conceito de eletronegatividade, contribuindo para uma confusão conceitual nos alunos e professores de Química. Desta forma, propõe-se que a abordagem do conceito de eletronegatividade seja realizada dentro de um contexto histórico, evitando-se o desconhecimento da gênese histórica dos conceitos, ou ainda, apesar desta gênese ser conhecida, não considerar alguns erros conceituais que podem ser induzidos no estudante pelo fato de não ser explicitado o processo de construção do conceito de eletronegatividade. Também, faz-se necessário o estabelecimento de conexões entre eletronegatividade e os conceitos com os quais este se constituiu em uma base interrelacional. O conceito de eletronegatividade, mesmo que apresentado de forma simples, poderia funcionar como um conceito estruturador no ensino e aprendizagem de Química, visto que apresenta relações com vários outros conceitos químicos. Precisamos conferir maior atenção à precisão dos conceitos, inclusive atentando para as mudanças de significado que os termos sofrem ao longo da história das ciências.

\section{REFERÊNCIAS}

1. Lopes, A. R. C.; Conhecimento escolar: ciência e cotidiano, EdUFRJ: Rio de Janeiro, 1999.

2. Bizzo, N.; Ciência fácil ou difícil? Ed. Ática: São Paulo, 1998.

3. Dominguini, L. A.; Revista Eletrônica de Ciências da Educação 2008, 7,1 .

4. Pauling, L.; The nature of the Chemical Bond, $3^{\text {rd }}$ ed., Cornell University Press: Ithaca, 1960.

5. Mülliken, R. S. J.; J. Chem. Phys. 1934, 782.

6. Allred, A. L.; Rochow, E. G.; J. Inorg. Nucl. Chem. 1958, 5, 264.

7. Sanderson, R. T. A.; Science 1951, 114, 670.

8. Pearson, R. G.; Acc. Chem. Res. 1990, 23, 1.

9. Keyan, L; Dongfeng, X.; Chinese Science Bulletin 2009, 54, 328.

10. Sanderson, R. T.; J. Chem. Educ. 1988, 65, 112.

11. Franzolin, F.; Dissertação de Mestrado, Universidade de São Paulo, Brasil, 2007.

12. Lopes, A. R. C.; Quim. Nova 1992, 15, 254.

13. Lopes, A. R. C.; Química Nova na Escola 1996, n 4, 22.

14. Balbino, K. C. M.; VII Encontro de Iniciação Científica da FAMINAS, Muriaé, Brasil, 2004.

15. Niaz, M.; Int. J. Sci. Educ. 2001, 23, 623. 